\title{
Mapping and evaluation of landscape ecological status using geographic indices extracted from remote sensing imagery of the Pearl River Delta, China, between 1998 and 2008
}

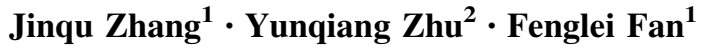

Received: 22 July 2014/ Accepted: 14 October 2015/Published online: 11 February 2016

(C) Springer-Verlag Berlin Heidelberg 2016

\begin{abstract}
This paper presents a method of mapping and monitoring ecological quality and environmental change using an ecological evaluation model (EEM), which is based on remote sensing data of the Pearl River Delta region in Guangdong, China. Five geographical indices were selected: Impervious Surface, Normalized Difference Vegetation Index, Land Surface Temperature, and Greenness and Brightness generated from the Tasseled Cap Transformation. These geographical indices are of ecological significance and they were used as variables to build the EEM through factor analysis. In addition, land use maps derived from remote sensing data were overlaid on these five index maps to analyze the effects of land use change on ecological status. Based on the EEM values, five levels of ecological zones were identified using a standarddeviation segmenting method. The results showed that the areas of the first and second levels decreased significantly, those of the third and fourth levels increased, and the area of the fifth level remained unchanged. It was established that the remote sensing method is practical for the analysis
\end{abstract}

Fenglei Fan

fanfenglei@gig.ac.cn

Jinqu Zhang

zhangjinqu@foxmail.com

Yunqiang Zhu

zhuyq@1reis.ac.cn

1 South China Normal University, Guangzhou 510631, Guangdong, China

2 State Key Laboratory of Resources and Environmental Information System, Institute of Geographic Sciences and Natural Resources Research, Chinese Academy of Sciences, Beijing 100101, China of ecological change, thus this work could be considered a case study for other ecological monitoring research.

Keywords Landscape ecology · Remote sensing · Indices $\cdot$ Model $\cdot$ Change

\section{Introduction}

Studies of landscape ecology permit investigation of the reciprocal interactions between ecological patterns and processes across a range of scales (Arvid and Andreas 2013). Population growth and human activities have increasingly affected much of the terrestrial biosphere and atmosphere in both intensity and extent, causing loss of habitat, degradation of ecosystem functions, and a reduction in value of ecosystem services for humans (Alcamo et al. 2005; Foley et al. 2005; Worley et al. 2008). Ecologists have improved their understanding of ecosystem processes, including those factors that influence the distribution of species and control extinction rates; however, the need for timely and accurate detection and prediction of changes in the natural environment has never been greater. Unfortunately, ecological data based on field surveys are unsuitable for direct application in a regional or global context, and models derived purely from local data are unlikely to be useful for predicting the global consequences of human activities. Therefore, ecologists and conservation biologists have turned to remote sensing, which can provide abundant data on the atmosphere and land surface at various spatial and temporal scales. Advances in remote sensing and geographical information system (GIS) technology have equipped ecologists with the tools to rapidly identify environmental change and to predict the consequences of such changes over time (Kerr and Ostrovsky 2003; Aldwaik and 
Pontius 2012; Huang et al. 2012). In comparison with other surveying techniques, remote sensing is unique in its capability to record large-scale land surface information with complete coverage, which can be compared with data from field samples (Groom et al. 2006; Inghe 2001).

Three types of remote sensing technique used in ecological and conservation research were described by Kerr and Ostrovsky (2003): the derivation of land cover data, integration of remote-sensing-derived parameters for ecosystem studies, and monitoring of changes in climate and habitat. The development of remote sensing techniques has meant that satellite remote sensing has become widely used for the derivation of the ecological and biophysical parameters used in ecological applications, such as monitoring vegetation cover change, urbanization, and desertification (Pontius et al. 2004, 2011; Fan et al. 2009). Comprehensive reviews have been conducted regarding the application of various types of satellite remote sensing data and techniques in studies of ecological status (e.g., Wang et al. 2010). Such applications have usually focused on one aspect of ecological status, and they have extracted information and analyzed the change of a single ecological factor, such as monitoring land cover change, and change analysis of wetlands and land surface temperature (LST) (Zhang et al. 2007; Bradley et al. 2009; Singh et al. 2014). Another aspect concerns relationships or impact analysis between ecological factors, particularly land use with other factors. Spatial patterns of land use have significant effects on the ecological processes, environment, and sustainable development within their boundaries and beyond (Luck and Wu 2002; Weng 2002; Jonathan et al. 2005). Therefore, it is necessary to investigate the relationships between spatial patterns of land use and urbanization within the same ecosystem to obtain a better understanding of the ecological processes (Luck and Wu 2002; Turner 2005). The correlation between land use and LST has also been studied and discussed in recent years (Liu and Weng 2008; Zhang et al. 2007). Li et al. (2011) investigated the effects and relationships of different urban land use features and their spatial patterns in relation to the urban heat island by analyzing the spatial correlation of LST and the Normalized Difference Vegetation Index (NDVI) in Shanghai. Improvements in techniques for retrieving various ecological data from remote sensing images mean that ecological evaluations based on such data will become an increasingly important research area. Carvalho-Santos et al. (2013) described a method for the evaluation of hydrological ecosystem services based on remote sensing. De Keersmaecker $(2014,2015)$ provided a framework to assess the reliability of ecosystem stability metrics in terms of the function of data characteristics. Remote sensing has become a method commonly used for ecological and conservation research because of the richness of the data and the variety of spatial and temporal coverage, especially with regard to larger spatial scales.

The objective of this study was to associate geographical indices, such as Impervious Surface (IS), NDVI, LST, Greenness, and Brightness, with ecological change using remote sensing imagery, and to understand how changes reflected in the geographical indices affect the ecological quality of a region. The intention was to explain the ecological and environmental changes of the Pearl River Delta (PRD) region based on five geographical indices, to design an evaluation model to map ecological quality and its temporal change.

\section{Study area}

The PRD (shaded area in Fig. 1; 22-23.6 $\mathrm{N}$, $112.6-114.4^{\circ} \mathrm{E}$ ) is located in southern China, adjacent to Hong Kong and Macao. Overall, 12 cities/counties are associated with this area: Shenzhen, Bao'an, Dongguan, Guangzhou, Huadu, Zengcheng, Panyu, Chancheng, Nanhai, Shunde, Zhongshan, and Zhuhai. The delta, which encompasses an area of $21,388 \mathrm{~km}^{2}$, has a subtropical climate. The average annual temperature is $21-23{ }^{\circ} \mathrm{C}$, and the average annual precipitation is $1600-2600 \mathrm{~mm}$ (Fan et al. 2008). Since the reform and opening up in the late 1970s, the PRD has become one of the largest urbanized regions in the world, and it is one of the leading economic regions and the most important manufacturing center in China.

\section{Data preparation}

Four Landsat-5 thematic mapper (TM) images from December 22, 1998 and December 1, 2008 were acquired for two adjacent scenes in each year. The path and row numbers of the scenes used in this research were 122/044 and 122/045. All the images were both rectified and unified based on the Transverse Mercator projection. Systematic geometric and radiometric corrections were performed prior to delivery by the Earth Resources Observation Systems Data Center, United States Geological Survey. The TM images from 2008 were used as references and the TM images from 1998 were then registered and rectified to the reference images using "image-to-image" methods by an image re-sampling algorithm based on the nearest neighbor technique. Image registration accuracy was measured by root mean square error with values $<0.5$ pixels.

\section{Collection of land use data}

A supervised maximum likelihood classification method was used for classifying the land use of the images from 1998 and 2008. The maximum likelihood algorithm is one of the most commonly used methods in the classification of 


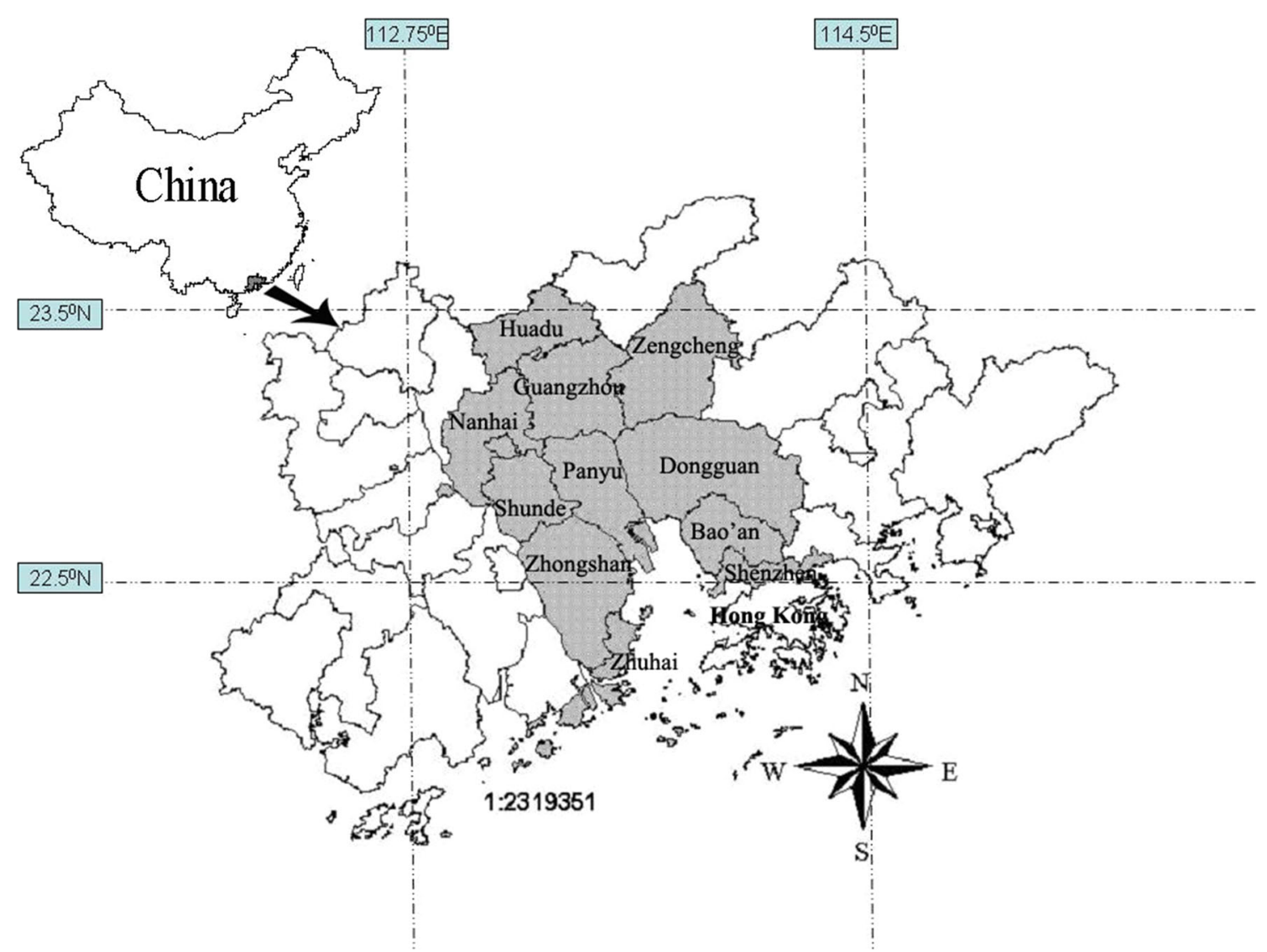

Fig. 1 Pearl River Delta study area

remote sensing imagery, which has been used, developed, and recommended by a number of authors (e.g., Srivastava et al. 2012, 2014a). Detailed equations for the method can be found in the work of Asmala and Shaun (2012). This study adopted nine land use classifications: Forest, Urban, Orchard, Development, Paddy, Farmland, Water, DikePond, and Grassland. The method calculates the probability that a pixel belongs to each of the candidate land use categories and each pixel is assigned to a class based on the maximum probability. To obtain a better selection of training samples, field surveys were conducted in the areas covered by the remote sensing images, and photographs reflecting the characteristics of the typical land use types are presented in Fig. 2. According to the report based on the Jeffries-Matusita distance, calculated using the Environment for Visualizing Images software (Table 1), the training samples had good separability between each other. The Jeffries-Matusita distance, which has a value between 0 and 2, is commonly used to reflect the separability of two class signatures: values close to 2 indicate a high degree of separability, which are acceptable when the value is $>1.8$ (Thomas et al. 1987, 2002).

Figure 3 shows the classification results for the images from 1998 and 2008. The accuracy assessment was performed using about 200 randomly generated sample points for verification via visual interpretation and statistical analysis. The overall accuracies of the land use classifications from 1998 and 2008 approach 82.6 and $80.5 \%$ (with Kappa values of 0.88 and 0.82 ), respectively (Table 2). The overall accuracy represents the percentage of correctly classified samples, calculated as the ratio of the total number of correctly classified pixels to the total number of pixels for all classes. The Kappa coefficient is another measure of classification accuracy, which has been described in detail by Asmala and Shaun (2012).

\section{Retrieval of land surface temperature (LST)}

The following equation, called the mono-window algorithm, can be used to retrieve LST from Band 6 of Landsat5 TM data (Qin et al. 2001):

$\mathrm{T}_{\mathrm{s}}=\frac{a_{6}\left(1-C_{6}-D_{6}\right)+\left[b_{6}\left(1-C_{6}-D_{6}\right)+C_{6}+D_{6}\right] T_{6}-D_{6} T_{\mathrm{a}}}{C_{6}}$,

where $T_{\mathrm{s}}, T_{6}$, and $T_{\mathrm{a}}$ are the retrieved LST, brightness temperature computed from Band 6 of the TM, and effective mean atmospheric temperature, respectively, 
Fig. 2 Typical land use types and associated characteristic photographs
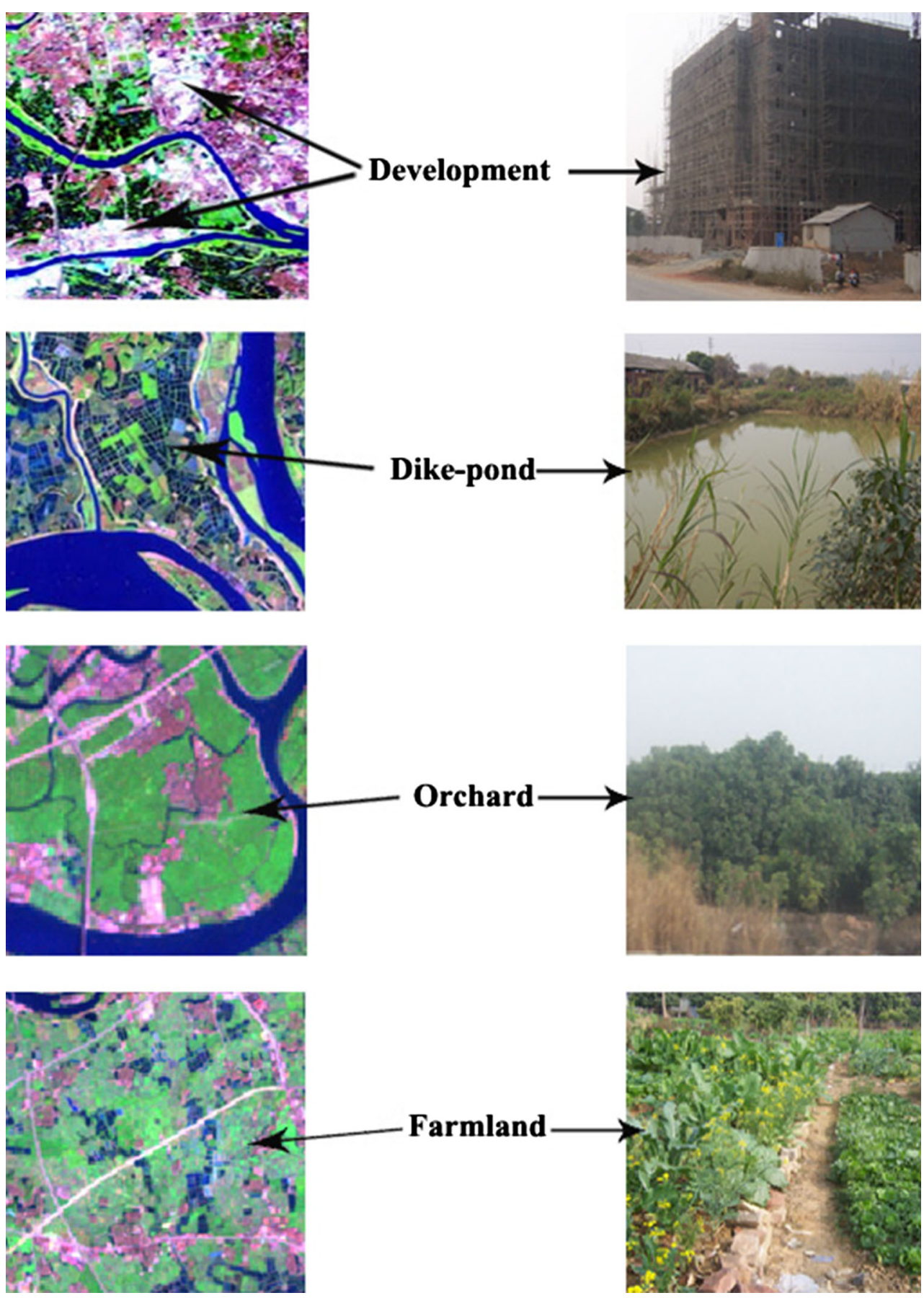

$a_{6}=-67.355351$ and $b_{6}=0.458606$ are constants of the algorithm when the LST is between 0 and $70{ }^{\circ} \mathrm{C}$, and $C_{6}$ and $D_{6}$ can be calculated using the equations below:

$C_{6}=\varepsilon_{6} \tau_{6}$,

$D_{6}=\left(1-\tau_{6}\right)\left[1+\left(1-\varepsilon_{6}\right) \cdot \tau_{6}\right]$,

where $\varepsilon_{6}$ stands for the ground surface emissivity and $\tau_{6}$ represents the atmospheric transmittance. According to the equations above, only three parameters are needed. The effective mean atmospheric temperature $\left(T_{\mathrm{a}}\right)$ was calculated using the near-surface air temperature, acquired from local weather stations. The effective mean atmospheric transmittance $\left(\tau_{6}\right)$ was calculated using the equations described in Qin et al. (2001) or Srivastava et al. (2014b) with water vapor as the parameter. The water vapor of the study area was estimated to be between 0.3 and $0.4 \mathrm{~g} / \mathrm{cm}^{2}$ according to weather station data. The ground surface emissivity $\left(\varepsilon_{6}\right)$ was prepared using software developed by 
Table 1 Separability matrix report of training samples calculated using environment for visualizing images software for images from 1998 and 2008

\begin{tabular}{|c|c|c|c|c|c|c|c|c|c|}
\hline & Water & Urban & Farmland & Grassland & Forest & Orchard & Development & Dike-Pond & Paddy \\
\hline \multicolumn{10}{|l|}{ Water } \\
\hline (1998) & & 1.9999 & 2.0000 & 2.0000 & 1.9999 & 2.0000 & 1.9999 & 1.8911 & 2.0000 \\
\hline (2008) & & 2.0000 & 2.0000 & 2.0000 & 2.0000 & 2.0000 & 2.0000 & 1.9221 & 1.9980 \\
\hline \multicolumn{10}{|l|}{ Urban } \\
\hline (1998) & 1.9999 & & 1.9815 & 1.8362 & 1.9995 & 1.9991 & 1.9779 & 1.9567 & 1.9974 \\
\hline (2008) & 2.0000 & & 1.9997 & 1.9870 & 1.9999 & 1.9998 & 1.9381 & 1.9883 & 1.9999 \\
\hline \multicolumn{10}{|l|}{ Farmland } \\
\hline (1998) & 2.0000 & 1.9815 & & 1.9606 & 1.9815 & 1.8626 & 1.9068 & 1.9921 & 1.9606 \\
\hline (2008) & 2.0000 & 1.9997 & & 1.9068 & 1.9997 & 1.8946 & 1.9999 & 1.9997 & 1.9986 \\
\hline \multicolumn{10}{|l|}{ Grassland } \\
\hline (1998) & 2.0000 & 1.8362 & 1.9606 & & 1.8362 & 1.8522 & 1.9999 & 1.9956 & 1.8143 \\
\hline (2008) & 2.0000 & 1.9870 & 1.9068 & & 1.8870 & 1.8902 & 2.0000 & 1.9999 & 1.8841 \\
\hline \multicolumn{10}{|l|}{ Forest } \\
\hline (1998) & 1.9999 & 1.9995 & 1.9815 & 1.8362 & & 1.8069 & 1.8362 & 1.9999 & 1.9655 \\
\hline (2008) & 2.0000 & 1.9999 & 1.9997 & 1.8870 & & 1.8759 & 1.9870 & 1.9999 & 1.9942 \\
\hline \multicolumn{10}{|l|}{ Orchard } \\
\hline (1998) & 2.0000 & 1.9991 & 1.8626 & 1.8522 & 1.8069 & & 1.9987 & 1.9858 & 1.8203 \\
\hline (2008) & 2.0000 & 1.9998 & 1.8946 & 1.8902 & 1.8759 & & 2.0000 & 1.9995 & 1.8277 \\
\hline \multicolumn{10}{|c|}{ Development } \\
\hline (1998) & 1.9999 & 1.9779 & 1.9068 & 1.9999 & 1.8362 & 1.9987 & & 1.9957 & 1.9993 \\
\hline (2008) & 2.0000 & 1.9381 & 1.9999 & 2.0000 & 1.9870 & 2.0000 & & 2.0000 & 2.0000 \\
\hline \multicolumn{10}{|c|}{ Dike-Pond } \\
\hline (1998) & 1.8911 & 1.9567 & 1.9921 & 1.9956 & 1.9999 & 1.9858 & 1.9957 & & 1.9362 \\
\hline (2008) & 1.9221 & 1.9883 & 1.9997 & 1.9999 & 1.9999 & 1.9995 & 2.0000 & & 1.9570 \\
\hline \multicolumn{10}{|l|}{ Paddy } \\
\hline (1998) & 2.0000 & 1.9974 & 1.9606 & 1.8143 & 1.9655 & 1.8203 & 1.9993 & 1.9362 & \\
\hline (2008) & 1.9980 & 1.9999 & 1.9986 & 1.8841 & 1.9942 & 1.8277 & 2.0000 & 1.9570 & \\
\hline
\end{tabular}

Zhang et al. (2006). Figure 4 shows the LST for 1998 and 2008 , for which the accuracy analysis was performed using the same method as in Zhang and Wang (2008).

\section{Impervious surface (IS)}

Impervious surface (IS) percentages for 1998 and 2008 were extracted from the TM images using the Linear Spectral Mixture Analysis (LSMA) method. This method assumes that the spectrum measured by a sensor is a linear combination of the spectra of all components within the pixel and that the spectral proportions of the components represent the percentages of the surface features. This method is widely used in remote sensing to estimate the fractional abundance of material present within an image pixel (Roberts et al. 1998; Daniel and Chein-I 2001). Because of the complex composition of urban landscapes and relatively coarse resolution of Landsat TM images, one pixel in a TM image can contain more than one type of surface feature. Thus, the LSMA method was adopted here for "un-mixing" the pixels. The LSMA equation can be expressed as:

$R_{i}=\sum_{k=1}^{n} f_{k} R_{i k}+E R_{i}$

where $i$ stands for the spectral band number, $k$ represents the end-member number, $R_{i}$ stands for the spectral reflectance of band $i$ that consists of several end-members, $f_{k}$ represents the percentage of end-member $k$ contained within the pixel, $R_{i k}$ stands for the known spectral reflectance of end-member $k$ within the pixel of band $i$, and $E R_{i}$ represents the error of band $i$. This study used a constrained least squares solution that assumed both the following conditions were satisfied: 

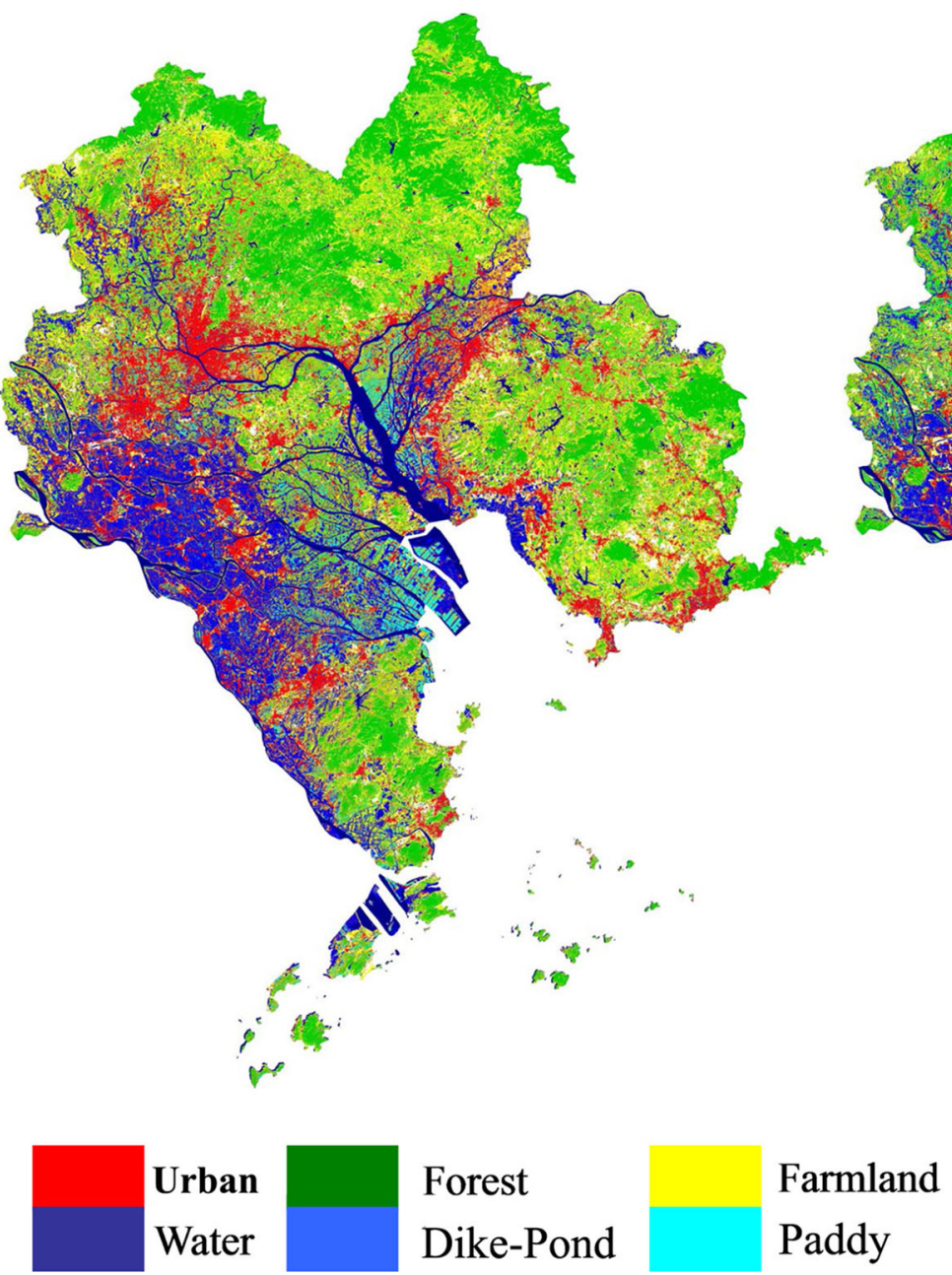

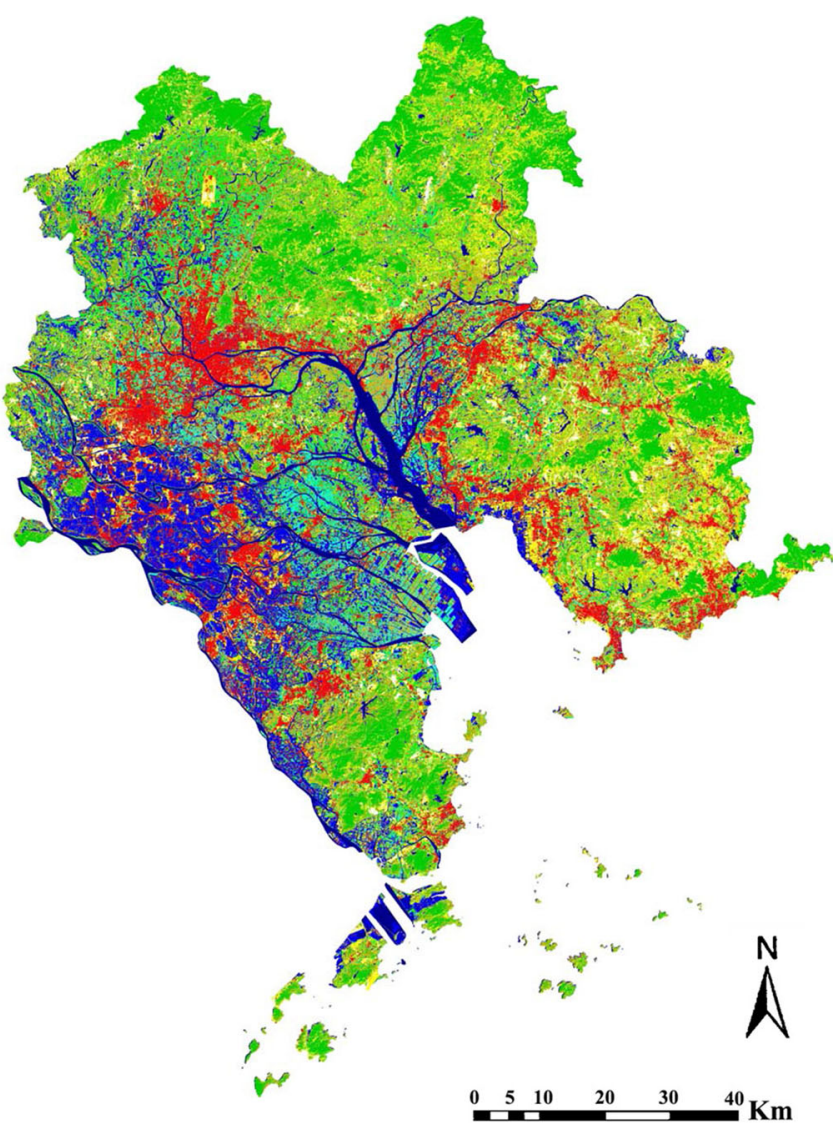

Orchard Development

Fig. 3 Classification images of the Pearl River Delta area: (left) 1998 and (right) 2008

Table 2 Accuracy of classification for each class in images from 1998 and 2008

\begin{tabular}{clllllllllll}
\hline Year & Water & Urban & Farmland & Grassland & Forest & Orchard & Development & Dike-Pond & Paddy & Overall accuracy & Kappa coefficient \\
\hline 1998 & 0.92 & 0.84 & 0.83 & 0.85 & 0.85 & 0.76 & 0.82 & 0.79 & 0.81 & 0.826 & 0.88 \\
2008 & 0.87 & 0.85 & 0.79 & 0.83 & 0.9 & 0.82 & 0.78 & 0.86 & 0.79 & 0.805 & 0.82 \\
\hline
\end{tabular}

$R_{i}=\sum_{k=1}^{n} f_{k} R_{i k}+E R_{i}$

$$
0 \leq f_{k} \leq 1 \text {. }
$$

The 1998 and 2008 IS images from the PRD are shown in Fig. 5. High-resolution images from Google Earth's Historical Imagery for 1998 and 2008 were used to evaluate the IS accuracy. Six hundred and fifty random samples were generated using a $3 \times 3$ sampling grid to eliminate the negative effects of geometric errors between the TM and Google Earth images. The root mean square errors for IS were 0.06 and 0.16 for 1998 and 2008, respectively.

\section{Other data}

In addition to land use, LST, and IS, the Greenness (G), Brightness (B), and NDVI were retrieved from the 1998 and 2008 TM images. Greenness and Brightness data were generated through the Tasseled Cap transformation (K-T transformation), which was proposed by Kauth and Thomas (1976) and initially used for Landsat MSS images. The $\mathrm{K}-\mathrm{T}$ transformation is a conversion of the original bands of an image into a new set of bands with defined interpretations that are useful for vegetation mapping. The first new band corresponds to the overall brightness of the image; the 

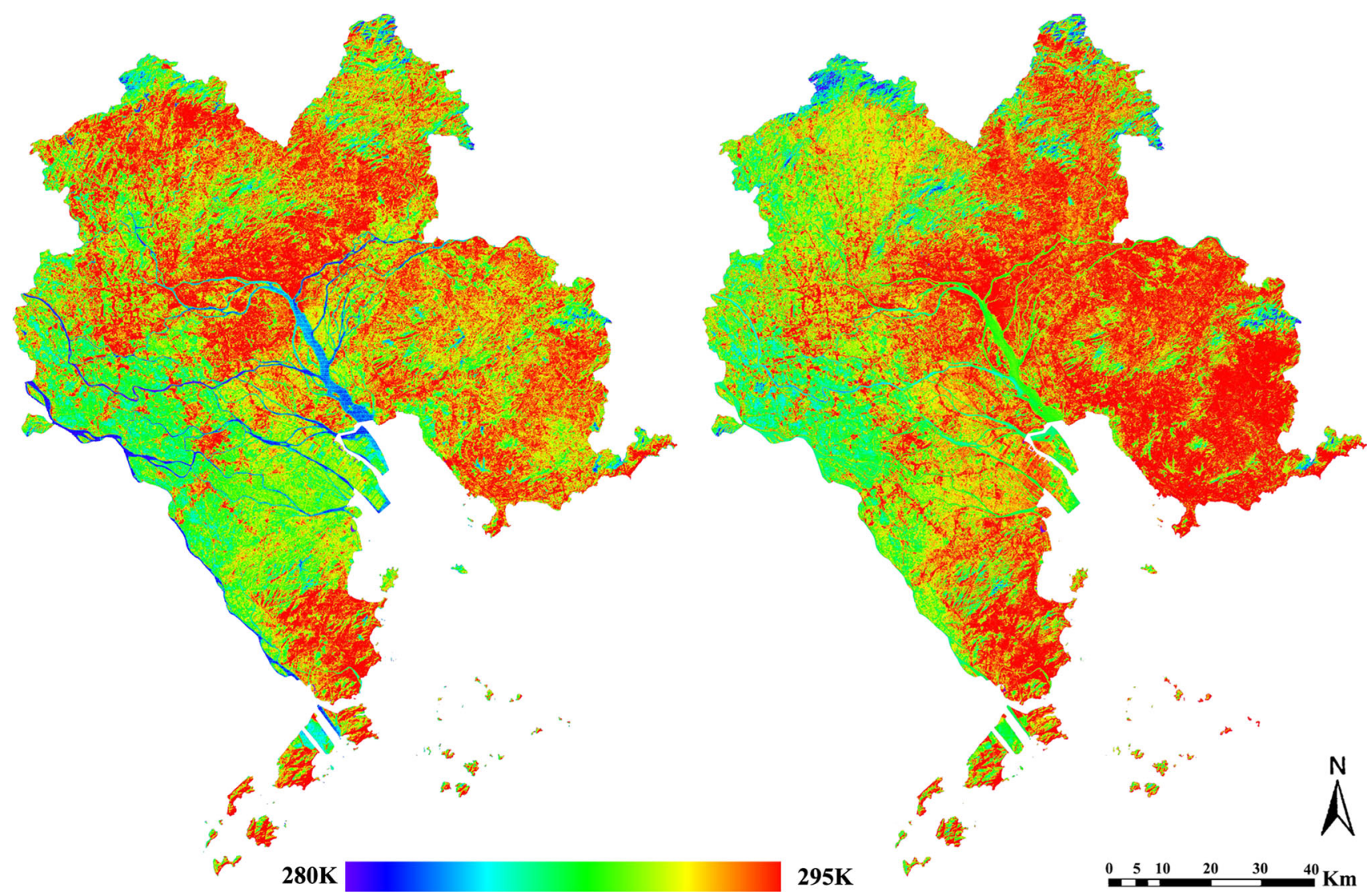

Fig. 4 Pearl River Delta land surface temperatures: (left) 1998 and (right) 2008

second band corresponds to greenness, and the third tasseled-cap band is often interpreted as an index of wetness. The first (Brightness) and second (Greenness) components of the $\mathrm{K}-\mathrm{T}$ transformation were used as indicators for the environmental evaluation. The process is performed directly using the function integrated in the Environment for Visualizing Images software.

NDVI is a popular indicator with which to assess vegetation health and it can be calculated using the following equation:

$\mathrm{NDVI}=(b 4-b 3) /(b 4+b 3)$,

where $\mathrm{b} 4$ is the reflectance in the near-infrared corresponding to Band 4 in the TM data and b3 is the red band in the TM data. The values of NDVI range between -1 and +1 . Vegetated areas, which have relatively high reflectance in the near-infrared wavelength and low reflectance in the visible wavelength, generally yield high NDVI values. NDVI is often used to estimate vegetation health and to monitor vegetation changes over time.

Among the factors retrieved from remote sensing imagery, LST is correlated directly with atmospheric temperature, and the $\mathrm{G} / \mathrm{B}$ index reflects vegetation health and the balance between thermal energy and moisture content.
Land use change, NDVI, and the G/B index were the principal sources of raw data used in this analysis of ecological change in the PRD area.

\section{Analytical methods}

Factor analysis was the primary method used in this research to develop the ecological evaluation model (EEM). Factor analysis attempts to represent a set of observed variables $\left(X_{1}, X_{2}, \ldots, X_{n}\right)$ in terms of a number of common factors in relation to a potentially lower number of unobserved variables (Tabachnick and Fidell 2001). It is assumed that the observed variables are correlated through sharing one or more underlying causes. Factor analysis reduces a correlation matrix to a few major factors, such that the variables within a factor are more highly correlated with each other than with the variables of another factor (Belton and Stewart 2001). The number of factors selected depends on the percentage of the variance explained by each factor. Usually, the first factor contains most of the variance within the data, and each successive factor contains progressively less of the variance (Tabachnick and Fidell 2001). If $X_{1}, X_{2}, \ldots, X_{n}$ are considered as the observed variables and $F_{1}, F_{2}, \ldots, F_{m}$ represent common 

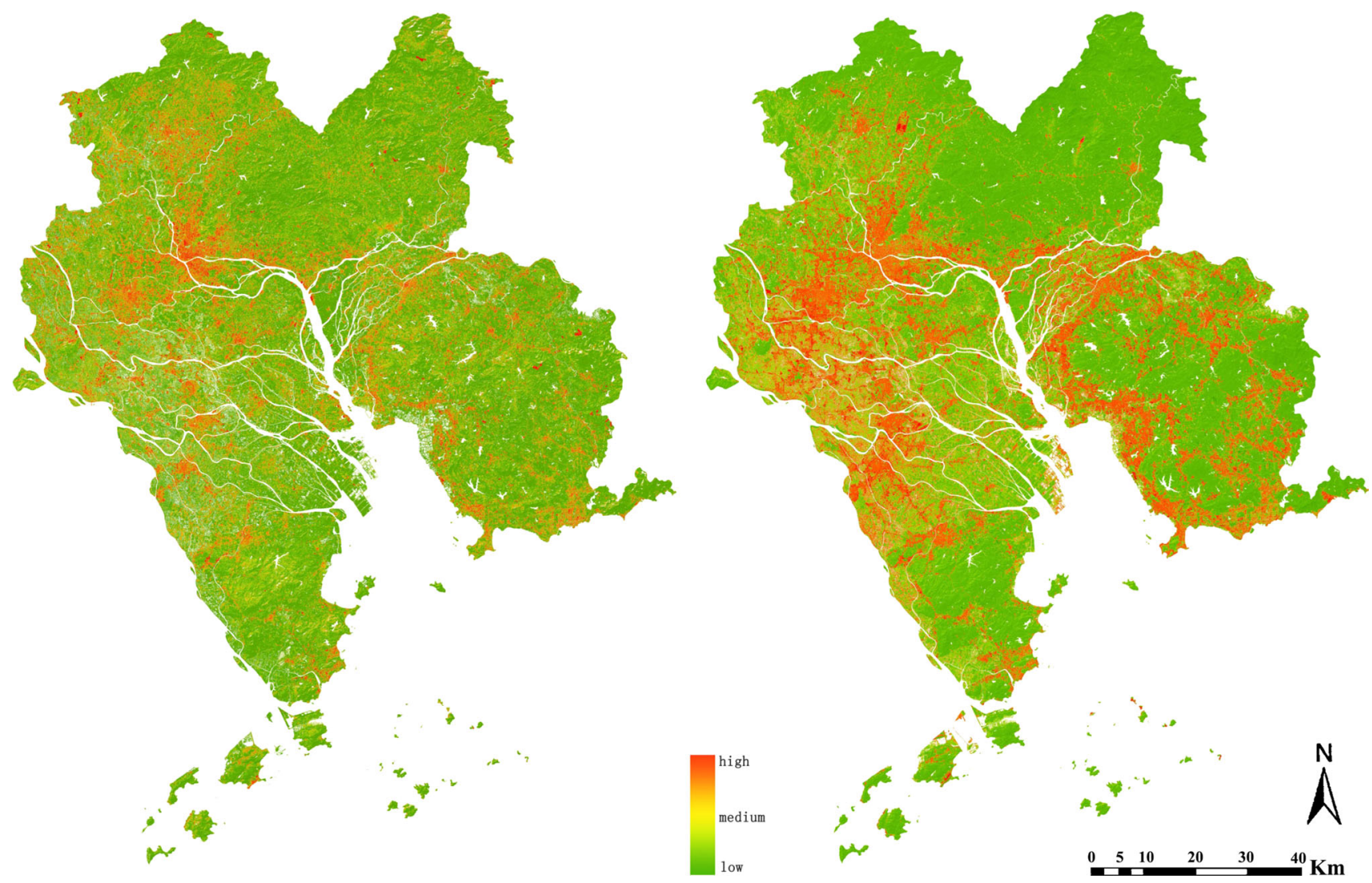

Fig. 5 Distribution of Impervious Surface percentages for the Pearl River Delta: (left) 1998 and (right) 2008

factors, then the variables may be expressed as linear functions of the factors, as below:

$X_{1}=a_{11} \times F_{1}+a_{12} \times F_{2}+\cdots+a_{1 m} \times F_{m}+e_{1}$

$X_{2}=a_{21} \times F_{1}+a_{22} \times F_{2}+\cdots+a_{2 m} \times F_{m}+e_{2}$

$X_{p}=a_{p 1} \times F_{1}+a_{p 2} \times F_{2}+\cdots+a_{p m} \times F_{m}+e_{p}$

where $a_{11}, a_{12}, \ldots, a_{p m}$ are factor loadings (coefficients) and $e_{1}, e_{2}, \ldots, e_{p}$ are independently distributed errors. They are all regression equations and factor analysis attempts to compute the coefficients that best reproduce the observed variables from the factors. When the factors are uncorrelated, they show the correlation between each variable and a given factor. Taking $a_{11}$ as an example, it shows the effect on variable $X_{1}$ of a one-unit increase in $F_{1}$. Therefore, the larger the loading, the stronger the correlation will be between variable $X_{1}$ and factor $F_{1}$.

Sometimes it can be beneficial to describe features of a research object using factors instead of original variables, because factors can reflect information related to the original variables. Common factors can be expressed as linear combinations of variables or samples, e.g., $F_{j}=$ $B_{j 1} \times X_{1}+B_{\mathrm{j} 2} \times X_{2}+\cdots+B_{j p} \times X_{p}, \quad(j=1, \quad \ldots, m)$. Such an equation is called a factor score function and it can be used to calculate factor scores for each sample. Because the number of equations $(m)$ is less than the number of variables $(p)$, factor scores cannot be calculated accurately, but estimates can be derived. Grice (2001) and Williams et al. (2010) have described a detailed implementation of this procedure and thus there is no need to repeat the description here.

\section{Results and discussion}

\section{Single-index analysis}

In this study, factor analysis was applied to build an EEM and to quantize the ecological levels of the PRD area using five geographical indices (IS, LST, NDVI, and the $G$ and $B$ factors generated from the $K-T$ transformation). Within a GIS environment, land use data from 1998 and 2008, derived from Landsat TM imagery, were converted to a vector format (polygons) based on specified thresholds. The resulting land use maps were then used to extract information with regard to IS, NDVI, LST, and G/B for every land use type. Average values of these five indices for each land use type are listed in Table 3. 
Table 3 Average values of five indices for each land use type in 1998 and 2008

\begin{tabular}{lcccccccr}
\hline Average value & Urban & Farmland & Grassland & Forest & Orchard & Development & Dike-Pond & Paddy \\
\hline 1998 NDVI & -0.004 & 0.007 & 0.006 & 0.018 & 0.003 & -0.005 & -0.012 & 0.002 \\
2008 NDVI & -0.007 & 0.002 & 0.003 & 0.013 & 0.001 & -0.002 & -0.010 & -0.001 \\
1998 LST (K) & 282.6 & 282.6 & 282.4 & 281.6 & 281.6 & 282.8 & 279.7 & 280.9 \\
2008 LST (K) & 290.6 & 290.6 & 290.3 & 288.2 & 289.9 & 291.0 & 287.8 & 289.7 \\
1998 G factor & 59.75 & 134.8 & 171.3 & 192.1 & 161.9 & 89.6 & 72.7 & 188.1 \\
2008 G factor & 57.7 & 107.9 & 121.0 & 189.0 & 156.9 & 61.3 & 75.5 & 127.5 \\
1998 B factor & 154.3 & 168.8 & 164.6 & 90.8 & 134.6 & 228.2 & 76.4 & 128.4 \\
2008 B factor & 146.6 & 167.1 & 163.0 & 89.7 & 125.0 & 225.4 & 90.5 & 137.8 \\
1998 IS (\%) & 54.0 & 31.0 & 42.0 & 13.0 & 9.3 & 69.0 & 0.2 & 0.4 \\
2008 IS (\%) & 67.0 & 42.0 & 39.0 & 9.8 & 9.4 & 70.0 & 0.3 \\
\hline
\end{tabular}

According to the data displayed in Table 3, Forest has the highest average NDVI value, followed by Farmland, Grassland, Orchard, Paddy, Urban, Development, and Dike-Pond. NDVI values for Urban, Farmland, Grassland, Forest, Orchard, and Paddy areas declined slightly from 1998 to 2008, which implies an ecological degradation of the entire PRD area.

Compared with the NDVI, the G index presents a different trend over the observation period. The values of the $\mathrm{G}$ index for different land use types changed from 1998 to 2008. The Urban $\mathrm{G}$ value remained stable, which illustrates the stability of the urban ecology; however, the values for Farmland, Grassland, and Development areas declined significantly, most likely because of changes in land use. Plant types and rainfall can also contribute to changes in the values of the $G$ index. The observed change in the $G$ index value for Development areas can be related to the degree of development within a particular region. In the PRD area, large areas of land have been converted to developed land. When cities expand, Development land is used accordingly, with some plant cultivation, which causes the value of the $G$ index to rise year by year.

The $B$ index has a symmetrical spatial distribution within the PRD area. There are a few spots with high B values throughout the PRD region, and small annual changes near the edges of the cities of Conghua and Guangzhou. In 1998, the study area had a very high B value over a large area; however, in 2008, this area had become very small and only one point can be seen in the
TM images. The cause for this change was the development of the Baiyun International Airport, which was under construction from 1998 to 2000. In addition, the B value of the Dongguan-Shenzhen area shows a rising tendency, which reveals the transformation of a large area to Development land and the emergence of bare land in this zone.

The IS changes for each land use type demonstrate three trends: (1) the IS data for Orchard, Development, DikePond, and Paddy areas show only minor changes, i.e., these land use types were stable; (2) the IS data for Urban and Farmland areas show large increases; and (3) the IS data for Grassland and Forest show smaller changes. According to Table 1, it can be seen that in the decade from 1998 to 2008, large areas of farmland, forest, and grassland have been converted to urban land use.

\section{Ecological analysis using the ecological evaluation model (EEM)}

To build the EEM, 1200 pixels (randomized and stratified based on land use) were selected and the values of the five indices described above were extracted. The SPSS ${ }^{\circledR}$ software package was used to perform the factor analysis according to the earlier description. In a first step, the Kaiser-Meyer-Olkin score (KMO) (0.921) and Bartlett's Test of Sphericity significance $(0.907)$ were calculated to check the suitability of the data for factor analysis. Usually, the KMO value varies between 0 and 1 . A value close to 0
Table 4 Ecology scores and associated color ranges

\begin{tabular}{llllll}
\hline EEM score & Color & Level of ecology & EEM score & Color & Level of ecology \\
\hline$-0.3378-0.0847$ & White & 5 & $1.4545-1.7930$ & Orange4 & 3 \\
$0.0847-0.5072$ & Blue3 & 5 & $1.7930-2.1316$ & Green1 & 2 \\
$0.5072-0.9297$ & Cyan & 4 & $2.1316-2.4702$ & Green3 & 1 \\
$0.9297-1.4545$ & Orange1 & 3 & $2.4702-3.0422$ & Green3 & 1 \\
\hline
\end{tabular}


implies that the sum of the partial correlations is large relative to the sum of the correlations, indicating that factor analysis is likely to be inappropriate. A value close to 1 indicates relatively compact patterns of correlation for which factor analysis could output distinct and reliable factors. Kaiser and Cerny (1979) suggest that factor analysis is acceptable when the KMO value is $>0.5$. However, values of $0.5-0.7,0.7-0.8,0.8-0.9$, and $>0.9$ are considered mediocre, good, great, and superb, respectively (Stevens 2002). For the data used in this study, the value was 0.921 , which falls into the range of being superb, implying that factor analysis was very appropriate for these data. A principal component analysis was used to extract factors with eigenvalues associated with each linear component calculated. According to the variance percentage of each
Fig. 7 Class maps of the five ecological status levels: $\left(a_{1}\right)$ and $\left(a_{2}\right)$ are the first ecological-level zones for 1998 and 2008, respectively; $\left(b_{1}\right)$ and $\left(b_{2}\right)$ are the second ecological-level zones for 1998 and 2008, respectively; $\left(c_{1}\right)$ and $\left(c_{2}\right)$ are the third ecological-level zones for 1998 and 2008, respectively; $\left(d_{1}\right)$ and $\left(d_{2}\right)$ are the fourth ecologicallevel zones for 1998 and 2008, respectively; and $\left(e_{1}\right)$ and $\left(e_{2}\right)$ are the fifth ecological-level zones for 1998 and 2008, respectively

component, the first principal component $\left(F_{1}\right)$ contributed $78.12 \%$ of the variance to the data; therefore, the first component was used as the EEM to assess the ecological quality and to map the ecological status of the PRD. Furthermore, a rotated factor matrix, which is a matrix of the factor loadings for each variable onto each factor, was generated using SPSS ${ }^{\circledR}$. Loadings of all the factors are

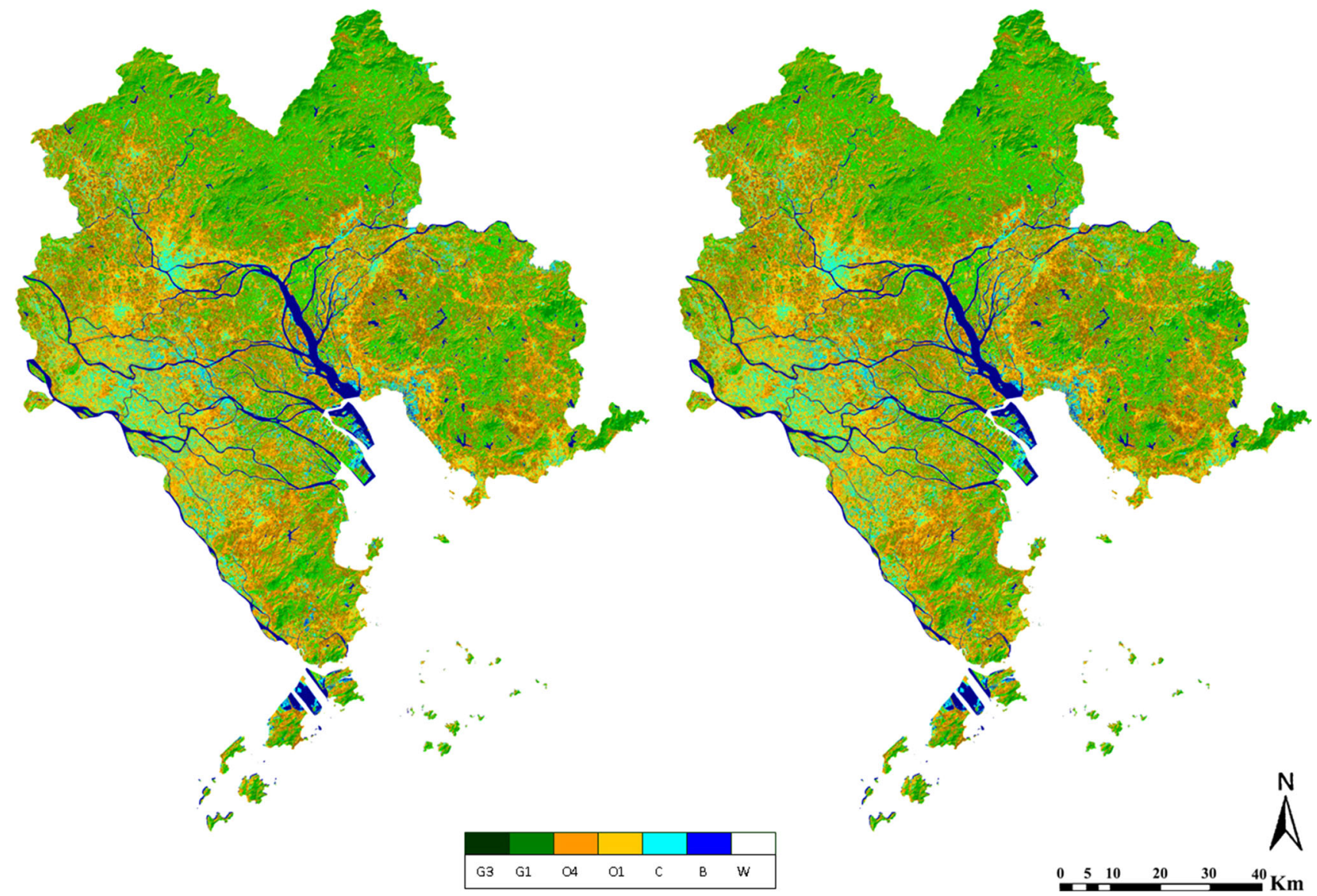

Fig. 6 Ecology maps based on the scores of the ecological evaluation model: (left) 1998 and (right) 2008

Table 5 Areas for each level of ecological zone (ha)

\begin{tabular}{llllll}
\hline Ecological zone & 1st level & 2nd level & 3rd level & 4th level & 5th level \\
\hline Score & $2.1316-3.0422$ & $1.793-2.1316$ & $0.9297-1.793$ & $0.5072-0.9297$ & -0.3378 to 0.5072 \\
1998 & $92,585.535$ & $241,714.029$ & $773,069.805$ & $120,219.722$ & $86,102.504$ \\
2008 & $27,683.604$ & $102,774.292$ & $951,596.991$ & $178,445.025$ & $53,191.683$ \\
Change & $-64,901.931$ & $-138,939.737$ & $178,527.186$ & $58,225.303$ & $-32,910.821$ \\
\hline
\end{tabular}



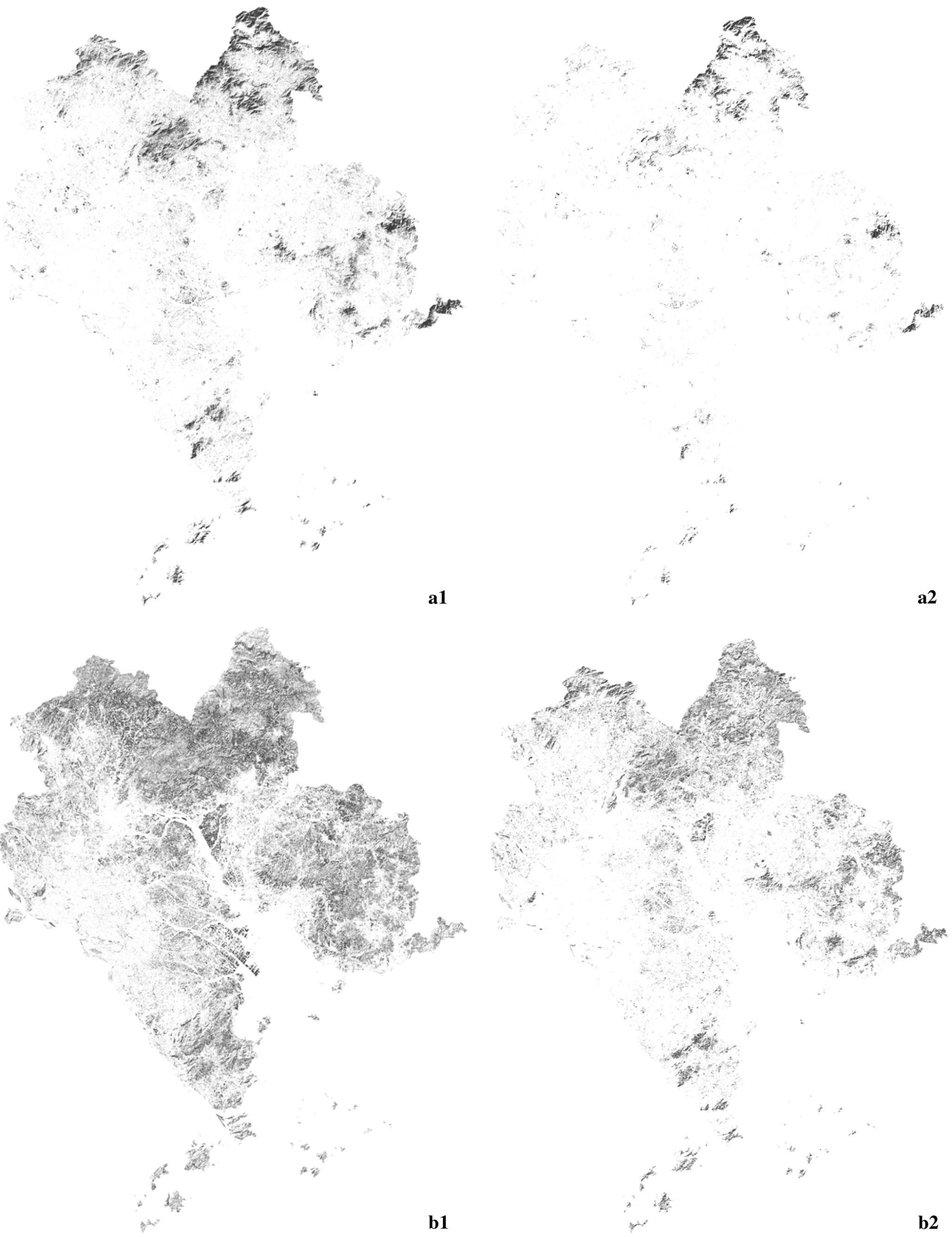

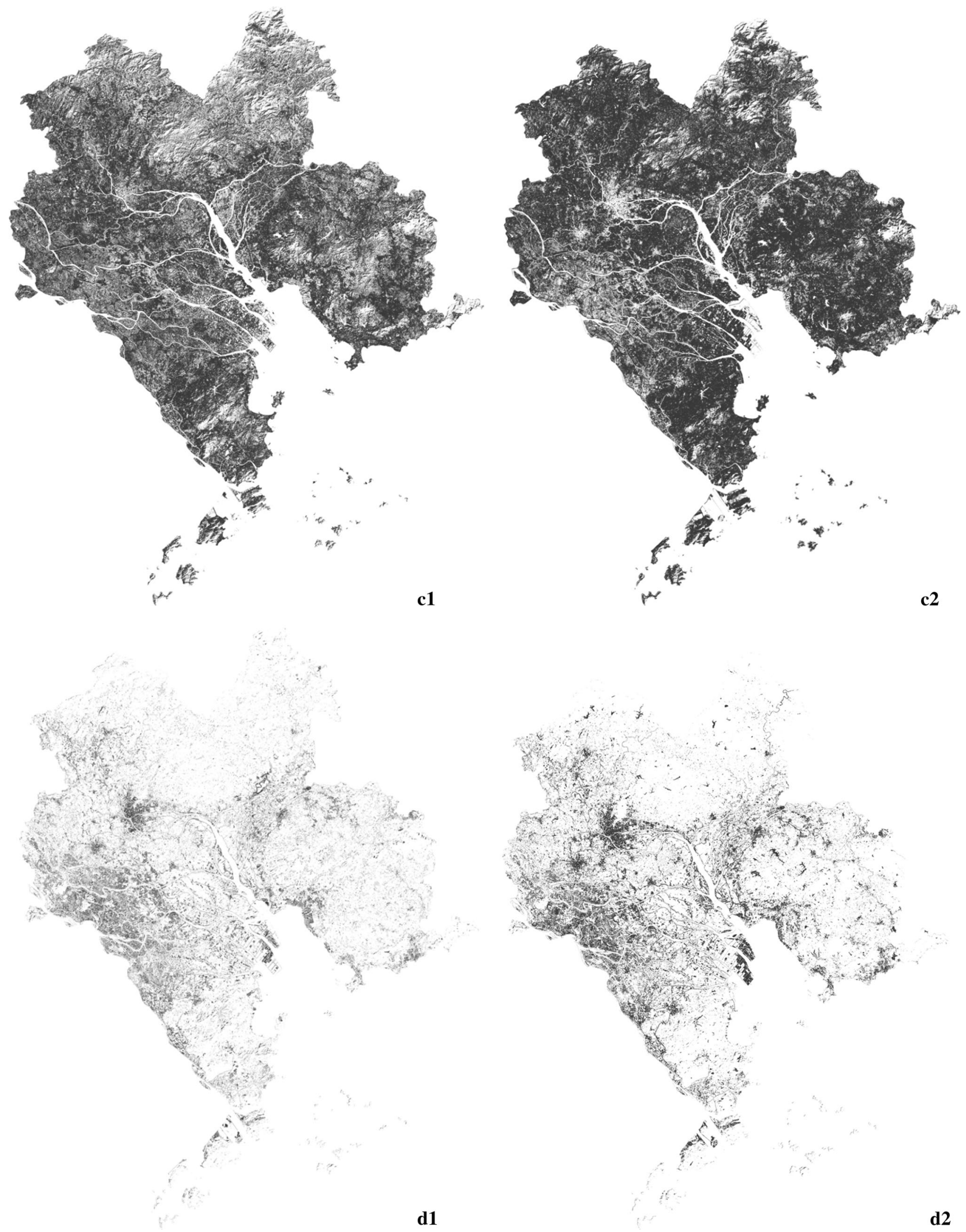

Fig. 7 continued 


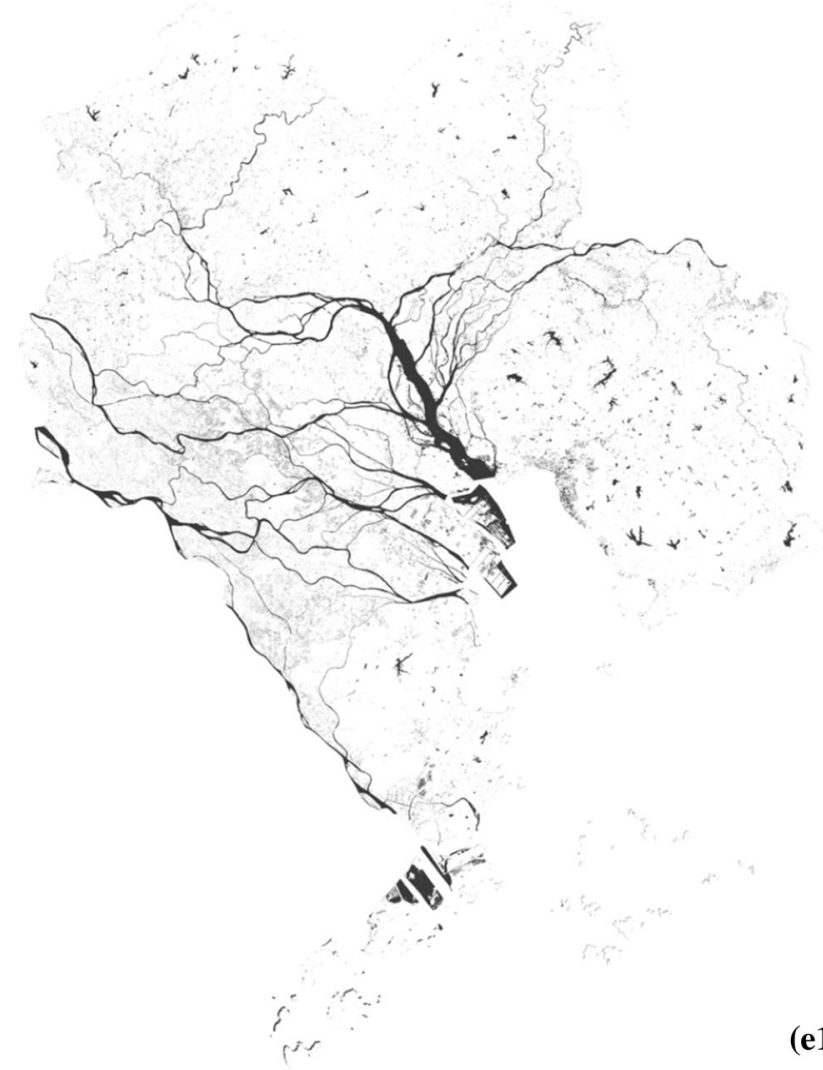

(e1)

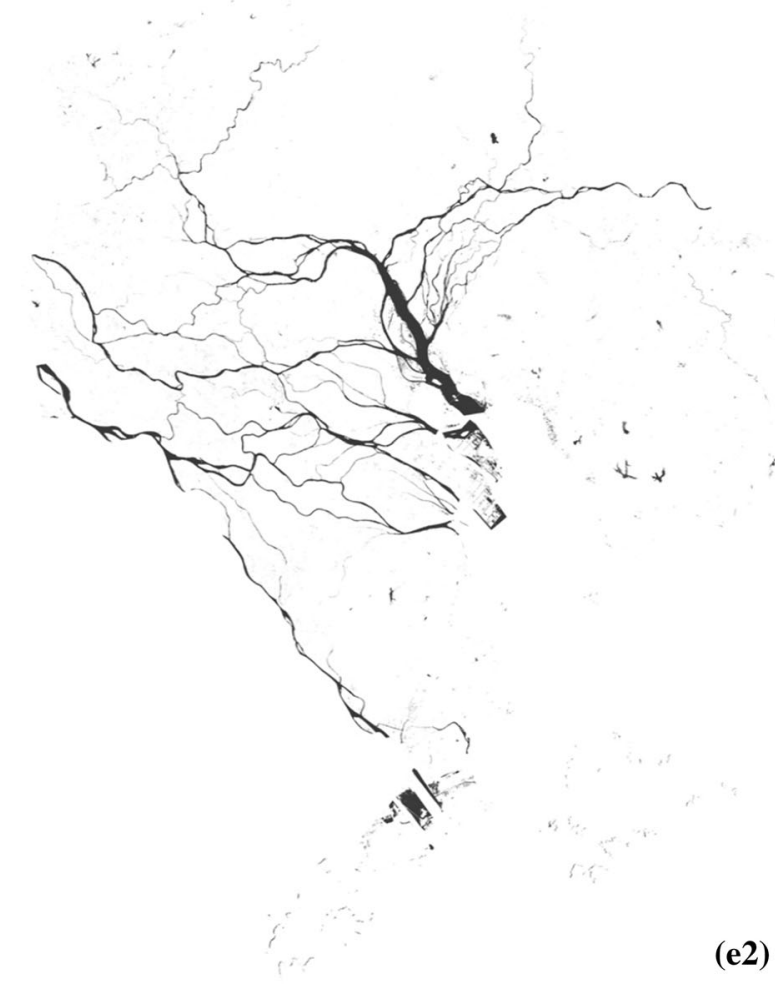

Fig. 7 continued

displayed in the rotated factor matrix. Component score coefficients were then computed with values of 0.921 for IS, 0.0762 for LST, 0.662 for NDVI, 0.592 for $G$, and 0.469 for $B$, respectively. These component coefficients values were the basis of building the equation of EEM. According to the analytical methods and equations of the previous section, the final EEM equation was calculated as follows:

$$
\begin{aligned}
F_{1}(\mathrm{EEM})= & 0.921 \times \mathrm{IS}+0.0762 \times \mathrm{LST}+0.662 \times \mathrm{NDVI} \\
& +0.592 \times G+0.469 \times B
\end{aligned}
$$

Using this equation, the $F_{1}$ value could be calculated for each pixel over the study region. For visual interpretation, the EEM was divided into five levels using the standarddeviation segmenting method proposed by Zhang and Wang (2008), based on which ecological-level maps were created for 1998 and 2008 (Table 4, Fig. 6). Simultaneously, areas for each ecological level were obtained using the threshold of each level (Table 5).

Table 5 and Fig. 6 illustrate a number of features. (1) The area of the first level decreased rapidly from $92,585.5$ ha in 1998 to $27,683.6$ ha in 2008. (2) The area of the second level decreased the most during the same period (by 138,939.7 ha). (3) The area of the third and fourth levels increased by 178,527.2 and 58,225.3 ha, respectively. (4) The area of the fifth level, which mostly consisted of water, remained largely unchanged.

Comparison of the two ecological maps from 1998 and 2008 (Fig. 6) revealed a considerable change in the overall ecological environmental quality in the PRD over a 10-year period. In 1998, the ecological area of the first level was concentrated mainly in Conghua, but it had shrunk to a region north of the city by 2008 , i.e., a decrease of $64,901.931$ ha had occurred in southern parts of Conghua. In 1998, second-level ecological areas were located in Conghua, Luogang, Panyu, Nansha on the eastern edge of Dongguan, and Shenzhen, but by 2008 they could only be found in Conghua and Shenzhen; an overall decrease in area of 138,939.7 ha. Conversely, over the studied 10-year period, the total areas of the third and fourth ecological levels increased dramatically. The area of the third ecological level expanded gradually to northern parts of the PRD area, and almost across the entire region by the end of 2008. Areas of the fourth ecological level were located in Foshan, Zhongshan, and Dongguan in 1998. Following 
economic development, the area of the fourth ecological level by 2008 had increased by 58,225.3 ha, concentrated mainly around Foshan and Dongguan. The ecological environment within the areas defined by these two types had become worse. The atrophication of high-quality ecological areas (first and second levels) and the expansion of low-quality ecological areas (third and fourth levels) indicate obvious deterioration of the ecological environment. Areas of the fifth ecological level (lowest-quality areas) did occur throughout the PRD region in 1998 but they were reduced to an area of $32,910.8$ ha by 2008 , especially in Foshan and Dongguan. There have been signs of a gradual recovery in the ecological condition, which suggest that despite economic development, the importance of protecting their ecological environment has been realized by humans.

Figure 7 and Table 5 show that in both 1998 and 2008, the first ecological-level zones of the PRD were located mainly in the north. These areas are mostly covered by forest, particularly the Baiyun Mountain Nature Preserve. Although the first ecological level had an overall area of nearly 100,000 ha, its area decreased by $64,901.9$ ha by 2008. A similar change occurred in the area of the second ecological level, which lost over half its area (a decrease from 241,714 to 102,774 ha), with a concurrent reduction in occupation. The areal decreases of these two levels indicate that the ecological quality experienced serious decline. In contrast, the third and fourth ecological-level zones increased in area by 178,527 and 58,225 ha, respectively. The fifth ecological-level zone includes mostly water, such as rivers, lakes, and reservoirs, and this zone decreased in area from 86,102 to 53,191 ha between 1998 and 2008, perhaps because of variations in rainfall during different seasons. It is believed that some of the first and second ecological-level zones were transformed into third and fourth levels because of human activities. Government and society have realized that ecological health is an important resource for humans, and that humans must participate actively in protecting their environment and restoring a deteriorating ecology.

\section{Conclusions}

Ecology is a complex issue that concerns the combination of abiotic (or physical) and biotic (or living) components. Different researchers have different views, different understandings, and different methods regarding the investigation of ecological problems, including environmental changes. Diverse methods and technologies have been applied over recent years, among which the technique of remote sensing has proven useful and effective for monitoring and evaluating ecological change.
In this study, a number of important geographical indices used for investigating land use (i.e., IS, NDVI, LST, Greenness, and Brightness) were selected and studied. They were all retrieved using the general methods of remote sensing image processing. Based on land use data from 1998 and 2008, a change analysis for each index was performed to reflect the ecological status of the PRD. It was established that NDVI values for the Urban, Farmland, Grassland, Forest, Orchard, and Paddy land uses declined slightly from 1998 to 2008, implying an ecological degradation of the entire PRD area. The other indices also showed various changes for the different land use types from 1998 to 2008. The results showed that the changes in the geographical indices reflect the changing ecological status, patterns, and processes, and that they are of ecological significance. The values of these indices were used as variables to build an EEM through factor analysis. Using the EEM, a comprehensive evaluation factor was constructed that combined the different geographical indices. Based on the EEM values, the zones of five ecological levels were identified using a standard-deviation segmenting method, which were then used to map the distribution of ecological zones in the PRD and to analyze the ecological changes. The statistical results of each level zone indicated that significant change has occurred over the 10-year period from 1998 to 2008. It was determined that ecological quality has undergone serious degradation, i.e., the first and second ecological-level zones had become largely transformed into third ecological-level zones, illustrating that the extent of high-quality ecological areas had diminished. Nevertheless, a concurrent increase in the size of the fourth ecological-level zone, and a decrease in the extent of the fifth ecological-level zone, indicated the existence of processes that were leading to ecological repair.

In studies such as this, uncertainties inherent in EEMs for large regions are a considerable concern. It is virtually impossible to have complete certainty regarding the analytical process that leads to decisions, because in the modern world, decision making almost always involves multiple stakeholders with multiple viewpoints. In most cases, the number of state variables in EEMs that require initialization is much larger than what is currently available. Consequently, it is necessary to create maps by spatial interpolation and interpretation of data points.

This study provided not only information about ecological change, but also data concerning the spatial change of ecological zones. Moreover, an integrated EEM was developed using five geographical indices and a macroscopic, quantitative ecological score was produced. In addition, degrees of ecological health were distinguished. Ultimately, it was shown that remote sensing methods are practical for the analysis of ecological change, thus this 
work could be considered as a case study for other ecological monitoring research.

Acknowledgments This work was supported by the National Nature Science Foundation of China (Grant No.: 41201432), Science and Technology Planning Project of Guangdong Province (2014A070711020), National Special Program on Basic Works for Science and Technology of China (No. 2013FY110900), Natural Science Foundation of Guangdong Province, China (Grant No.: S2013010014097).

\section{References}

Alcamo J, van Vuuren D, Cramer W (2005) Changes in ecosystem services and their drivers across the scenarios. In: Carpenter SR, Pingali PL, Bennett EM, Zurek MB (eds) Ecosystems and human well-being, Scenarios, findings of the Scenarios Working Group, Millennium Ecosystem Assessment. Island Press, Washington, pp 297-373

Aldwaik S, Pontius R (2012) Intensity analysis to unify measurements of size and stationarity of land changes by interval. Landsc Urban Plan 106(1):103-114

Arvid B, Andreas Z (2013) To model the landscape as a network: a practitioner's perspective. Landsc Urban Plan 119:35-43

Asmala A, Shaun Q (2012) Analysis of maximum likelihood classification on multispectral data. Appl Math Sci 6(129):6425-6436

Belton V, Stewart T (2001) Multiple criteria decision analysis: an integrated approach. Kluwer Academic, Boston

Bradley AM, William GC, van der Valk AG (2009) Spatial distribution of historical wetland classes on the Des Moines Lobe, Iowa. Wetlands 29(4):1146-1152

Carvalho-Santos C, Marcos B, Espinha MJ, Alcaraz-Segura J, Hein LG, Pradinho HH (2013) Evaluation of hydrological ecosystem services through remote sensing. Earth Observation of Ecosystem Services, CRC Press Taylors and Francis group, Boca Raton, pp 229-260

Daniel CH, Chein-I C (2001) Fully constrained least squares linear spectral mixture analysis method for material quantification in hyperspectral imagery. IEEE Trans Geosci Remote Sens 39(3):529-545

De Keersmaecker W, Lhermitte S, Honnay O, Farifteh J, Somers B, Coppin P (2014) How to measure ecosystem stability? An evaluation of the reliability of stability metrics based on remote sensing time series across the major global ecosystems. Glob Change Biol 47(20):2149-2161

De Keersmaecker W, Lhermitte S, Tits L, Honnay O, Somers B, Coppin P (2015) Resilience and the reliability of spectral entropy to assess ecosystem stability. Glob Change Biol. doi:10.1111/ gcb.12799

Fan F, Wang Y, Wang Z (2008) Temporal and spatial change detecting (1998-2003) and predicting of land use and land cover in Core corridor of Pearl River Delta (China) by using TM and ETM+ images. Environ Monit Assess 137(1-3):127-147

Fan F, Wang Y, Qiu M, Wang Z (2009) Evaluating the temporal and spatial urban expansion patterns of Guangzhou from 1979 to 2003 by remote sensing and GIS methods. Int J Geogr Inf Sci 23(11):1371-1388

Foley JA, De Fries R, Asner GP, Barford C, Bonan G, Carpenter SR et al (2005) Global consequences of land use. Science 309:570-574

Grice J (2001) Computing and evaluating factor scores. Psychol Methods 6:430-450
Groom G, Mucher C, Ihse M, Wrbka T (2006) Remote sensing in landscape ecology: experiences and perspectives in a European context. Landscape Ecol 21(3):391-408

Huang J, Pontius J, Robert G, Li Q, Zhang Y (2012) Use of intensity analysis to link patterns with processes of land change from 1987 to 2007 in a coastal watershed of southeast China. Appl Geogr 34:371-384

Inghe O (2001) The Swedish landscape monitoring programmer: current status and prospects for the near future. In: Groom G, Reed $\mathrm{T}$ (eds) Strategic landscape monitoring for the Nordic countries (Tema Nord 2001:523). Nordic Council of Ministers, Copenhagen, pp 61-67

Jonathan AF, Ruth DF, Gregory PA, Carol B, Gordon B, Stephen RC, Chapin FS, Michael TC et al (2005) Global consequences of land use. Science 309:570-574

Kaiser H, Cerny B (1979) Factor analysis of the image correlation matrix. Educ Psychol Meas 39:711-714

Kauth RJ, Thomas GS (1976) The tasselled cap-a graphic description of the spectral-temporal development of agricultural crops as seen by LANDSAT. LARS Symposia, Paper 159

Kerr J, Ostrovsky M (2003) From space to species: ecological applications for remote sensing. Trends Ecol Evol 18(6):299-305

Li J, Song C, Cao L, Zhu F, Meng X, Wu J (2011) Impacts of landscape structure on surface urban heat islands: a case study of Shanghai, China. Remote Sens Environ 115:3249-3263

Liu H, Weng Q (2008) Seasonal variations in the relationship between landscape pattern and land surface temperature in Indianapolis. Environ Monit Assess 144:199-219

Luck M, Wu J (2002) A gradient analysis of urban landscape pattern: a case study from the phoenix metropolitan region, Arizona. USA Landsc Ecol 17(4):327-339

Pontius J, Robert G, Emily S, Menzie M (2004) Detecting important categorical land changes while accounting for persistence. Agric Ecosyst Environ 101(2-3):251-268

Pontius J, Robert G, Marco M (2011) Death to Kappa: birth of quantity disagreement and allocation disagreement for accuracy assessment. Int J Remote Sens 32(15):4407-4429

Qin Z, Karnieli A, Berliner P (2001) A mono-algorithm for retrieving land surface temperature from Landsat TM data and its' application to the Israel-Egypt border region. Int J Remote Sens 18:583-594

Roberts DA, Batista GT, Pereira ILG, Waller EK, Nelson BW (1998) Change identification using multitemporal spectral mixture analysis: applications in eastern Amazonia. In: Lunetta RS, Elvidge CD (eds) Remote sensing change detection: environmental monitoring methods and applications. Taylor and Francis Ltd, London, pp 137-158

Singh SK, Srivastava PK, Gupta M, Thakur JK, Mukherjee S (2014) Appraisal of land use/land cover of mangrove forest ecosystem using support vector machine. Environ Earth Sci 71(5):2245-2255

Srivastava PK, Han D, Rico-Ramirez MA, Bray M, Islam T (2012) Selection of classification techniques for land use/land cover change investigation. Adv Space Res 50(9):1250-1265

Srivastava PK, Han D, Rico-Ramirez MA, Bray M, Islam T, Gupta M, Dai Q (2014a) Estimation of land surface temperature from atmospherically corrected LANDSAT TM image using 6S and NCEP global reanalysis product. Environ Earth Sci. doi:10.1007/ s12665-014-3388-1

Srivastava PK, Mehta A, Gupta M, Singh SK, Islam T (2014b) Assessing impact of climate change on Mundra mangrove forest ecosystem, Gulf of Kutch, western coast of India: a synergistic evaluation using remote sensing. Theoret Appl Climatol 72:5183-5196 
Stevens J (2002) Applied multivariate statistics for the social sciences, 4th edn. Lawrence Erlbaum Associates, Mahwah

Tabachnick B, Fidell L (2001) Principal components and factor analysis. In using multivariate statistics, 4th edn. Allyn \& Bacon, Needham Heights, pp 582-633

Thomas IL, Ching NP, Benning VM, D'Aguanno JA (1987) A review of multi-channel indices of class separability. Int J Remote Sens 8(3):331-350

Thomas V, Treitz P, Jelinski D, Miller J, Lafleur P, McCaughey JH (2002) Image classification of a northern peatland complex using spectral and plant community data. Remote Sens Environ 84(1):83-99

Turner M (2005) Landscape ecology in North America: past, present and future. Ecology 86(8):1967-1974

Wang K, Franklin S, Guo X, Cattet M (2010) Remote sensing of ecology, biodiversity and conservation: a review from the perspective of remote sensing specialists. Sensors 10(11):9647-9667

Weng Q (2002) Land use change analysis in the Zhujiang Delta of China using satellite remote sensing, GIS and stochastic modeling. J Environ Manag 64:273-284
Williams B, Brown T, Onsman A (2010) Exploratory factor analysis: a five-step guide for novices. Australas J Paramed 8(3):1-13

Worley J, Vassar M, Wheeler D, Barnes L (2008) Factor structure of scores from the maslach burnout inventory: a review and Meta analysis of 45 exploratory and confirmatory factor analytic studies. Educ Psychol Measur 68:797-823

Zhang J, Wang Y (2008) Study of the relationships between the spatial extent of surface urban heat islands and urban characteristic factors based on Landsat ETM+ data. Sensors 11(8):7453-7468

Zhang J, Wang Y, Li Y (2006) A C ++ program for retrieving land surface temperature from the data of Landsat TM/ETM+ $b$ and 6. Comput Geosci 32(10):1796-1805

Zhang J, Wang Y, Wang Z (2007) Change analysis of land surface temperature based on robust statistics in the estuarine area of Pearl River (China) from 1990 to 2000 by Landsat TM/ ETM + data. Int J Remote Sens 28(10):2383-2390 